\title{
Association of FOXO3 Blood DNA Methylation with Cancer Risk, Cancer Survival, and Mortality
}

\author{
Chenglong Yu ${ }^{1}\left(\right.$, Allison M. Hodge ${ }^{2,3}$, Ee Ming Wong ${ }^{1,4}$, Jihoon Eric Joo ${ }^{5,6}$, Enes Makalic ${ }^{3}(\mathbb{D}$, \\ Daniel Schmidt ${ }^{7}$, Daniel D. Buchanan ${ }^{5,6,8}$, John L. Hopper ${ }^{3}$, Graham G. Giles ${ }^{1,2,3}$, Melissa C. Southey ${ }^{1,2,4}$ \\ and Pierre-Antoine Dugué ${ }^{1,2,3, *}$
}

Citation: Yu, C.; Hodge, A.M.; Wong, E.M.; Joo, J.E.; Makalic, E.; Schmidt, D.; Buchanan, D.D.;

Hopper, J.L.; Giles, G.G.;

Southey, M.C.; et al. Association of FOXO3 Blood DNA Methylation with Cancer Risk, Cancer Survival, and Mortality. Cells 2021, 10, 3384. https://doi.org/10.3390/ cells10123384

Academic Editors: Salvatore Fusco and Maria Rita Rippo

Received: 26 October 2021 Accepted: 26 November 2021 Published: 1 December 2021

Publisher's Note: MDPI stays neutral with regard to jurisdictional claims in published maps and institutional affiliations.

Copyright: (c) 2021 by the authors. Licensee MDPI, Basel, Switzerland. This article is an open access article distributed under the terms and conditions of the Creative Commons Attribution (CC BY) license (https:/ / creativecommons.org/licenses/by/ $4.0 /)$.
1 Precision Medicine, School of Clinical Sciences at Monash Health, Monash University, Clayton, VIC 3168, Australia; chenglong.yu@monash.edu (C.Y.); ming.wong@vcgs.org.au (E.M.W.); graham.giles@cancervic.org.au (G.G.G.); melissa.southey@monash.edu (M.C.S.)

2 Cancer Epidemiology Division, Cancer Council Victoria, Melbourne, VIC 3004, Australia; allison.hodge@cancervic.org.au

3 Centre for Epidemiology and Biostatistics, Melbourne School of Population and Global Health, The University of Melbourne, Parkville, VIC 3010, Australia; emakalic@unimelb.edu.au (E.M.); j.hopper@unimelb.edu.au (J.L.H.)

4 Department of Clinical Pathology, Melbourne Medical School, The University of Melbourne, Parkville, VIC 3010, Australia

5 Colorectal Oncogenomics Group, Department of Clinical Pathology, Melbourne Medical School, The University of Melbourne,

Parkville, VIC 3010, Australia; ji.joo@unimelb.edu.au (J.E.J.); daniel.buchanan@unimelb.edu.au (D.D.B.)

6 Victorian Comprehensive Cancer Centre, University of Melbourne Centre for Cancer Research, Parkville, VIC 3010, Australia

7 Department of Data Science and AI, Faculty of Information Technology, Monash University, Clayton, VIC 3168, Australia; daniel.schmidt@monash.edu

8 Genomic Medicine and Family Cancer Clinic, Royal Melbourne Hospital, Parkville, VIC 3000, Australia

* Correspondence: pierre-antoine.dugue@monash.edu

Abstract: Genetic variants in FOXO3 are associated with longevity. Here, we assessed whether blood DNA methylation at FOXO3 was associated with cancer risk, survival, and mortality. We used data from eight prospective case-control studies of breast $(n=409$ cases), colorectal $(n=835)$, gastric $(n=170)$, kidney $(n=143)$, lung $(n=332)$, prostate $(n=869)$, and urothelial $(n=428)$ cancer and B-cell lymphoma $(n=438)$. Case-control pairs were matched on age, sex, country of birth, and smoking (lung cancer study). Conditional logistic regression was used to assess associations between cancer risk and methylation at $45 \mathrm{CpGs}$ of FOXO3 included on the HumanMethylation450 assay. Mixed-effects Cox models were used to estimate hazard ratios (HR) and 95\% confidence intervals $(\mathrm{CI})$ for associations with cancer survival (total $n=2286$ deaths). Additionally, using data from 1088 older participants, we assessed associations of FOXO3 methylation with overall and cause-specific mortality $(n=354$ deaths). Methylation at a CpG in the first exon region of FOXO3 (6:108882981) was associated with gastric cancer survival (HR $=2.39,95 \%$ CI: $1.60-3.56$, $\left.p=1.9 \times 10^{-5}\right)$. Methylation at three CpGs in TSS1500 and gene body was associated with lung cancer survival $\left(p<6.1 \times 10^{-5}\right)$. We found no evidence of associations of FOXO3 methylation with cancer risk and mortality. Our findings may contribute to understanding the implication of FOXO3 in longevity.

Keywords: FOXO3; epigenetics; age-related outcome; longevity-related SNP; matched casecontrol study

\section{Introduction}

Genetic variation within the gene $\mathrm{FOXO} 3$ was first shown to be strongly associated with lifespan using C. elegans models [1-4]. Genetic variants in human homologs of this gene were subsequently reported to be associated with longevity in several cohorts 
worldwide, including participants of different ancestries [5-11]. To our knowledge, three functional longevity-associated single nucleotide polymorphisms (SNP) in FOXO3 have been identified: rs2802292, through its role in cellular stress response and apoptosis [12]; and rs12206094 and rs4946935, through their enhancer activity and role in mRNA expression [13]. In the largest GWAS to date [14], minor allele carriers of the variant rs2802292, together with carriers of rs10457180, which is also in FOXO3 and in strong linkage disequilibrium $\left(\mathrm{r}^{2}=0.64\right)$ with rs2802292 [15], were found to have an $8 \%$ higher and $9 \%$ lower odds, respectively, of surviving to the 90th percentile age of the population. The rs2802292 minor G-allele has been demonstrated to have protective effects on several specific age-related disorders, such as lower incidence of cancer and heart disease, in particular, coronary artery disease, and fewer bone fractures [11].

Epigenetic changes such as DNA methylation are thought to play a major role in tumourigenesis through their influence on various mechanisms, in particular, gene expression and genomic stability. DNA methylation is dependent on the one-carbon metabolism pathway, a major pathway in cancer [16], and consists of the addition of methyl groups (CH3) to cytosines at $\mathrm{CpG}$ dinucleotides, using DNA methyltransferases to form 5-methylcytosines (5-mC) [17]. Several studies have shown that DNA methylation in cancer-related genes measured in peripheral blood may be associated with cancer risk. Examples include hypermethylation of the BRCA1 promoter region, which was found to be associated with increased risk of early onset breast cancer, and tumours from cases showing blood hypermethylation appear to have similar pathological features as BRCA1 mutated tumours [18]. Blood DNA hypermethylation of an intragenic locus in ATM, a breast cancer predisposition gene, was also found to be associated with increased risk of breast cancer [19]. These examples highlight the relevance of constitutional DNA methylation measured in blood as indicative of a potential mechanism conferring an increased risk of disease. While FOXO3 is not primarily known as a major cancer predisposition gene, it is considered to be a tumour suppressor due to its role in regulating the immune system, inflammation [20], and oxidative stress [21], as well as cell proliferation, DNA damage, metabolism, and apoptosis [22]. Several studies have found that dysregulation of FOXO3 was associated with cancer progression and poor prognosis [23-25]. Furthermore, FOXO3 circular RNA has also been shown to play important regulatory roles in initiation and progression of several cancer types (breast, prostate, bladder, gastric, leukemia, etc.) [26-28]. Alterations in DNA methylation at the FOXO3 gene could therefore represent an additional, non-genetic mechanism affecting gene expression and causing cancer and premature death. Although the extent to which constitutional methylation changes may affect gene expression is not fully understood, there is value in assessing the association of blood DNA methylation with risk of and survival from cancer, as a major disease contributing to reduced longevity.

The aim of this study was to assess the association of DNA methylation at the FOXO3 gene measured in peripheral blood with several age-related outcomes: cancer risk, cancer survival, and mortality.

\section{Materials and Methods}

\subsection{Study Samples}

The Melbourne Collaborative Cohort Study (MCCS) is a prospective study of 41,513 adult participants (24,469 women) aged between 27 and 76 years (99\% aged $40-69$ ) when recruited between 1990 and 1994. Southern European migrants were oversampled to extend the range of lifestyle-related exposures [29]. Participants were contacted again between 2003 and 2007 and completed similar questionnaires and physical/clinical examinations. Blood samples were taken at baseline and follow-up from $99 \%$ and $64 \%$ of participants, respectively. Baseline samples were stored as dried blood spots on Guthrie cards for the majority $(73 \%)$, as peripheral blood mononuclear cell samples for $25 \%$, and as buffy coat samples for $2 \%$ of the participants. Follow-up samples were stored as buffy coat aliquots and dried blood spots on Guthrie cards. 
Study participants provided informed consent in accordance with the Declaration of Helsinki, and the study was approved by Cancer Council Victoria's Human Research Ethics Committee.

\subsection{Methylation Case-Control Studies}

Eight matched case-control studies nested in the MCCS were conducted to investigate the prospective association between blood DNA methylation and the risk of breast $(n=409$ cases), colorectal $(n=835)$, gastric $(n=170)$, kidney $(n=143)$, lung $(n=332)$, prostate $(n=869)$, and urothelial $(n=428)$ cancer and mature B-cell lymphoma $(n=438)$ [30-32]. Cases and controls were matched on age at blood draw, sex, country of birth (Australia/New Zealand, Greece, Italy, or United Kingdom/other) and sample type (peripheral blood mononuclear cells, dried blood spots or, buffy coats) using incidence density sampling. For the lung cancer study, controls were also matched on smoking history at the time of blood collection. To minimise batch effects, samples from each matched case-control pair were plated to adjacent wells on a same slide of the assay, with plate, slide, and position of the matched pairs assigned randomly. DNA was extracted from peripheral blood taken at the time of recruitment (1990-1994), except for 151 case-control pairs of the urothelial cancer study, for which blood samples were taken at the follow-up visit in 2003-2007. The DNA source was dried blood spots, peripheral blood mononuclear cells, or buffy coats for $70 \%, 28 \%$, and $2 \%$ of participants, respectively.

\subsection{Methylation Longitudinal Study}

Methylation measures were repeated at follow-up (2003-2007) for 1100 participants who were selected as controls in the methylation case-control studies. DNA was extracted from blood samples collected on Guthrie cards at follow-up (these participants also had their baseline sample collected on a Guthrie card). After quality control, DNA methylation data were available for a subset of 1088 of the controls (Table 1). Samples collected at follow-up were used to assess associations with mortality.

Table 1. Characteristics of the Melbourne Collaborative Cohort Study participants included in the analysis.

\begin{tabular}{|c|c|c|c|}
\hline \multirow[b]{2}{*}{ Participant Characteristic } & \multicolumn{2}{|c|}{ Matched Case-Control Pairs } & \multirow[b]{2}{*}{$\begin{array}{l}\text { Follow-Up Sample } \\
\qquad(n=1088)\end{array}$} \\
\hline & $\begin{array}{l}\text { Cases of Overall Cancer } \\
\qquad(n=3481)\end{array}$ & $\begin{array}{c}\text { Controls } \\
(n=3481)\end{array}$ & \\
\hline Age at blood draw, median [IQR] & $60.8[54.1-65.9]$ & $60.8[53.9-65.6]$ & $69.9[62.8-75.6]$ \\
\hline \multicolumn{4}{|l|}{ Sex: } \\
\hline Male, $n(\%)$ & $2125(61 \%)$ & $2125(61 \%)$ & $740(68 \%)$ \\
\hline Female, $n(\%)$ & $1356(39 \%)$ & $1356(39 \%)$ & $348(32 \%)$ \\
\hline \multicolumn{4}{|l|}{ Country of birth: } \\
\hline Australia/New-Zealand, $n(\%)$ & $2380(68 \%)$ & $2367(68 \%)$ & $831(77 \%)$ \\
\hline Greece, $n(\%)$ & $350(10 \%)$ & $361(10 \%)$ & $44(4 \%)$ \\
\hline Italy, $n(\%)$ & $520(15 \%)$ & $520(15 \%)$ & $89(8 \%)$ \\
\hline UK/other, $n(\%)$ & $231(7 \%)$ & $233(7 \%)$ & $124(11 \%)$ \\
\hline \multicolumn{4}{|l|}{ Blood sample type: } \\
\hline Dried blood spots, $n(\%)$ & $2412(69 \%)$ & $2412(69 \%)$ & \multirow[b]{3}{*}{$1088(100 \%)$} \\
\hline Peripheral blood mononuclear cells, $n(\%)$ & $873(25 \%)$ & $873(25 \%)$ & \\
\hline Buffy coats, $n(\%)$ & $196(6 \%)$ & $196(6 \%)$ & \\
\hline \multicolumn{4}{|l|}{ Smoking status: } \\
\hline Current, $n(\%)$ & $490(14 \%)$ & $472(14 \%)$ & $62(6 \%)$ \\
\hline Former, $n(\%)$ & $1377(40 \%)$ & $1337(38 \%)$ & $478(44 \%)$ \\
\hline Never, $n(\%)$ & $1613(46 \%)$ & $1671(48 \%)$ & $548(50 \%)$ \\
\hline Smoking pack-years, median [IQR] & $1.6[0-28.5]$ & $0.75[0-25.7]$ & - \\
\hline Body mass index $\left(\mathrm{kg} / \mathrm{m}^{2}\right)$, median [IQR] & $26.8[24.4-29.6]$ & $26.7[24.4-29.3]$ & $26.8[24.2-29.4]$ \\
\hline Alcohol consumption a (g/day), median [IQR] & $4.3[0-17.7]$ & $4.3[0-17.0]$ & $8.8[0-23.0]$ \\
\hline
\end{tabular}

a Alcohol consumption was reported for the past week at baseline and in the past 12 months at follow-up. 


\subsection{Quality Control of DNA Methylation Data}

DNA methylation was measured using the Infinium HumanMethylation450K (HM450) assay (Illumina, Inc., San Diego, CA, USA). Quality control details for processing methylation beta values have been reported previously [33]. M-values, calculated as $\log _{2}$ (beta/(1-beta)), were then used for the analyses since these are thought to be more statistically valid for detection of differential methylation [34]. In this study, we focused on $45 \mathrm{CpGs}$ of the FOXO3 gene that were available on the HM450 assay (chromosome 6, hg19 positions $108,881,028$ to $109,005,977)$. We used the Illumina annotation file to classify CpGs by functional regions (TSS1500, TSS200, 5'UTR, 1st exon, gene body, and 3'UTR).

\subsection{Genetic Data}

We also included genetic data for four longevity-related SNPs in FOXO3 (rs12206094, rs2802292, rs10457180 and rs4946935, Figure 1) available in 4306 MCCS participants including 2134 cancer cases and 2172 controls, after quality controls and exclusion of genetically related participants. Genotypes were obtained using the Infinium OncoArray-500K BeadChip (Illumina, San Diego, CA, USA) [29,35] and imputed using the Michigan imputation server [36] and IMPUTE version 2 [37] with the 1000 Genomes Project dataset (phase 3) as the reference panel. To avoid bias due to confounding by shared environment among close relatives, the 4306 participants were confirmed to be unrelated, i.e., any pair among them was with a genetic relationship $>0.05$ (4th degree or closer relationship) [38].

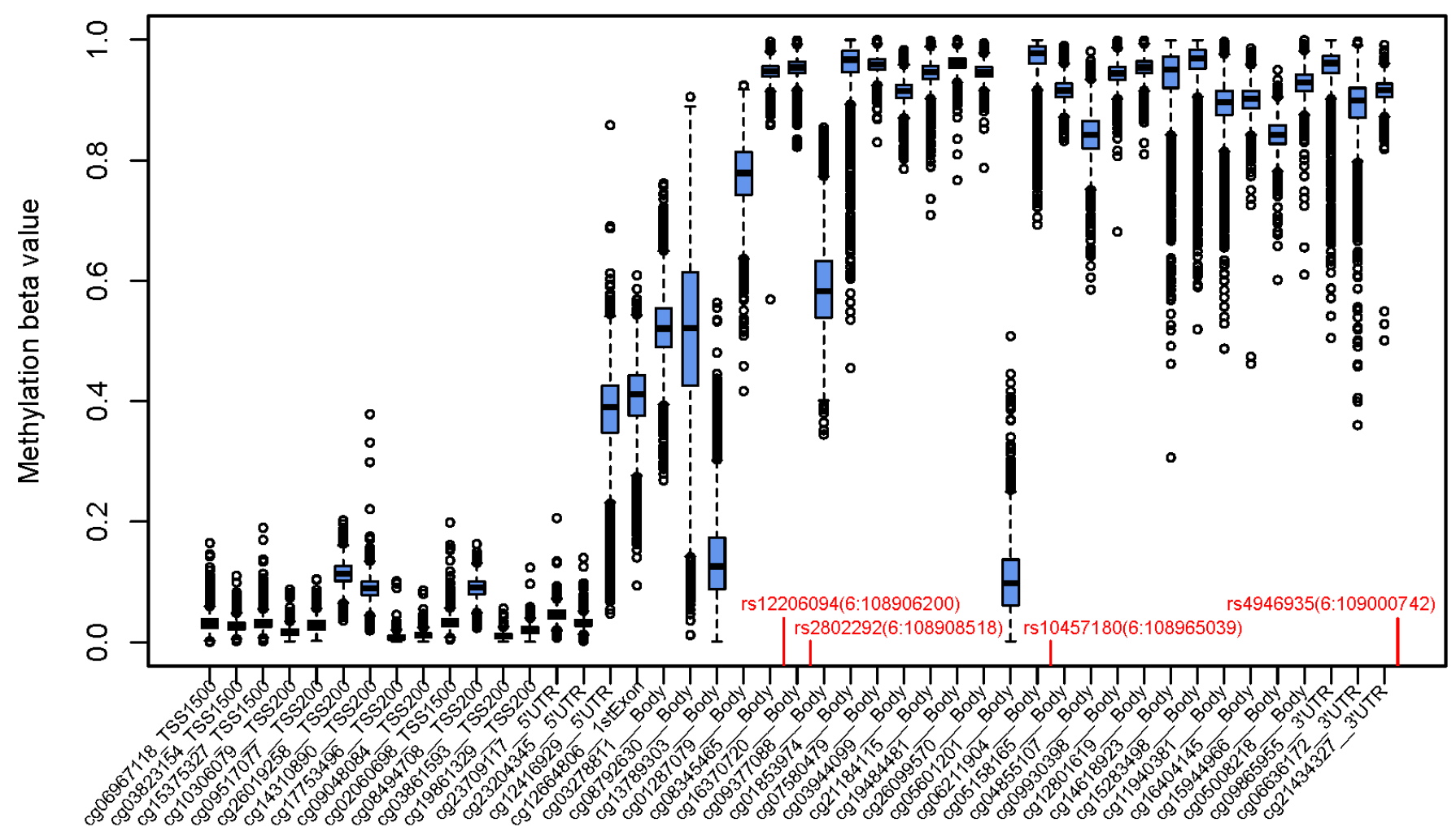

Figure 1. Relative position of SNPs associated with longevity and CpGs available on the HM450 assay (and their distributions of methylation values [boxplots showing median, interquartile range, and range] of 3481 control participants) of the FOXO3 gene.

\subsection{Vital Status}

Vital status up to 31 December 2019 was ascertained through record linkage to the Victorian Registry of Births, Deaths, and Marriages (via the Victorian Cancer Registry) and the National Death Index (via the Australian Institute of Health and Welfare). These registries were considered to be virtually complete up to 31 October 2019 and 31 August 2015 (cause 
of death), respectively. Causes of death were classified as follows, using the International Classification of Disease version 10: cancer: ICD-10 C00 to D49; cardiovascular disease (CVD): ICD-10 I00 to I99; other-cause: all other ICD codes, and missing $(n=2)$.

\subsection{Statistical Analysis}

\subsubsection{Effect of FOXO3 SNPs on Methylation}

To assess the potential influence of underlying genetic variants on our findings, we first corrected DNA methylation values using linear mixed models with M-values as the outcome, age, sex, sample type, white blood cell proportions (estimated using the Houseman algorithm [39]), and 20 genetic principal components to account for population structure as fixed effects, and study, plate, and slide of the assay as random effects, similar to a previous publication [38]. We then used linear regression to assess associations between the corrected M-values at the $45 \mathrm{CpG}$ and genetic values at the four variants. This analysis was undertaken in all 4306 samples and separately in the 2172 controls (to avoid potential collider bias). We considered associations to be significant after Bonferroni correction for multiple comparisons across four SNPs and 45 CpG sites $\left(p=0.05 /(45 \times 4)=2.78 \times 10^{-4}\right)$.

\subsubsection{Cancer Risk}

We assessed associations between DNA methylation at the $45 \mathrm{CpG}$ and risk of eight specific cancer types and risk of overall cancer, using conditional logistic regression models to estimate odds ratio (OR) and 95\% confidence intervals (CI), expressed per standard deviation (SD) of the methylation values. In Model 1.1, we adjusted for white blood cell composition (percentage of CD4 + T cells, CD8 + T cells, B cells, NK cells, monocytes and granulocytes, estimated using the Houseman algorithm [37]) and for age and country of birth to correct for small imbalances in the matching. Sex and sample type were exactly matched between cases and controls so were not adjusted for. Model 1.2 was additionally adjusted for the main lifestyle-related factors that affect blood DNA methylation [40-42]: smoking status (current/former/never) and pack-years (log-transformed), alcohol consumption in the previous week (grams/day, continuous), and body mass index (BMI, continuous); matched participant pairs with missing values in any of these confounders (breast cancer: $n=1$ pair, colorectal cancer: $n=17$, gastric cancer: $n=2$, kidney cancer: $n=2$, lung cancer: $n=3$, prostate cancer: $n=11$, urothelial cancer: $n=3$, mature B-cell lymphoma: $n=6$, and overall cancer: $n=42$ ) were excluded from the Model 1.2 analysis. For the overall cancer analysis, where a participant was diagnosed with more than one specific cancer type, we only included the first diagnosis $(n=3481)$, Table 1 . We considered associations with risk of cancer to be significant after Bonferroni correction for multiple comparisons across nine studies and $45 \mathrm{CpG}$ sites $\left(p=0.05 /(45 \times 9)=1.23 \times 10^{-4}\right)$.

\subsubsection{Cancer Survival}

We used mixed-effects Cox models [43] (Models 2.1 and 2.2) to estimate hazard ratios (HR) per SD for the associations between M-values at the $45 \mathrm{CpG}$ sites and risk of death (all causes) following cancer diagnosis. The survival analysis was thus restricted to cancer cases. Age was used as the underlying timescale [44], and time at risk was calculated from the date of cancer diagnosis to the date of death, date of departure from Australia, or end of follow-up (31 October 2019). For the overall cancer survival analysis, where a participant was diagnosed with several cancers, we considered only their first cancer diagnosis to calculate follow-up time $(n=3481$, among which 2185 deaths were observed). Number of deaths by cancer type was as follows: breast cancer: $n=160$, colorectal cancer: $n=549$, gastric cancer: $n=145$, kidney cancer: $n=84$, lung cancer: $n=312$, prostate cancer: $n=478$, urothelial cancer: $n=258$, and mature B-cell lymphoma: $n=300$. In Model 2.1, we adjusted for age, sex, country of birth, sample type, and white blood cell proportions as fixed effect variables and assay plate and slide as random effect variables. Model 2.2 was additionally adjusted for smoking status and pack-years, alcohol consumption, and BMI as fixed effect variables. For the overall cancer survival analysis, the models were also adjusted for 
cancer type (study) as a random effect variable. Cases with missing values in any of the lifestyle-related confounders (smoking status and pack-years, alcohol consumption, and BMI) were excluded from the Model 2.2 analyses: colorectal cancer: $n=13$, kidney cancer: $n=1$, prostate cancer: $n=7$, urothelial cancer: $n=2$, mature B-cell lymphoma: $n=4$, and overall cancer: $n=27$. We used the same $p$-value threshold as for the cancer risk analyses to detect associations $\left(p=1.23 \times 10^{-4}\right)$.

\subsubsection{Overall and Cause-Specific Mortality}

We used data from the 1088 controls who had repeated methylation measures at follow-up (Table 1) to assess the association of FOXO3 methylation with mortality. We used mixed effects Cox models to estimate hazard ratios for the association between methylation $\mathrm{M}$-values and mortality using age as the underlying time scale and time at risk calculated from the date of follow-up visit to the date of death, date of departure from Australia, or end of follow-up (31 October 2019); these models were adjusted for age, sex, country of birth, sample type, and white blood cell proportions as fixed effect variables, and assay plate and slide as random effect variables (Model 3.1) and additionally for smoking status and pack-years, alcohol consumption, and BMI (Model 3.2). For the latter, participants with missing values in any of the confounders measured at follow-up were excluded $(n=56)$. In cause-specific analyses, deaths from other causes than that of interest were censored, which is a way to model the cause-specific hazard function, appropriately taking the competing risk of other-cause death into account. We considered associations to be significant using the Bonferroni correction for multiple comparisons across four outcomes and $45 \mathrm{CpG}$ sites $\left(p=0.05 /(45 \times 4)=2.78 \times 10^{-4}\right)$.

All statistical analyses were performed using $R$ version 3.6.0.

\section{Results}

The characteristics of the MCCS samples used for investigating risk of cancer overall are presented in Table 1. Compared with controls, cases were more frequently past and current smokers and had greater smoking pack-years. The characteristics of the samples for each of the eight individual cancer case-control studies (breast, colorectal, gastric, kidney, lung, prostate, and urothelial cancers and mature B-cell lymphoma) nested within the MCCS are detailed in Table S1.

The positions of $\mathrm{FOXO} 3 \mathrm{CpGs}$ relative to SNPs were found to be associated with longevity, and the distribution of methylation beta values of the 3481 controls across the FOXO3 gene are shown in Figure 1. The Pearson correlation matrix of methylation values of the 3481 controls at the $45 \mathrm{CpGs}$ across FOXO3 is shown in Figure 2 and Table S2, showing generally weak correlations, typically lower than 0.3 ; these were null between promoter regions (TSS1500, TSS200 and 5'UTR) and the first exon, positive within the promoter and gene body regions, and negative between promoter and gene body regions. None of the four longevity-related SNPs in FOXO3 were found to have a significant effect on any of the $45 \mathrm{CpGs}$ in the region (all $p>2.78 \times 10^{-4}$ and variance explained $<0.4 \%$, Table S3). 


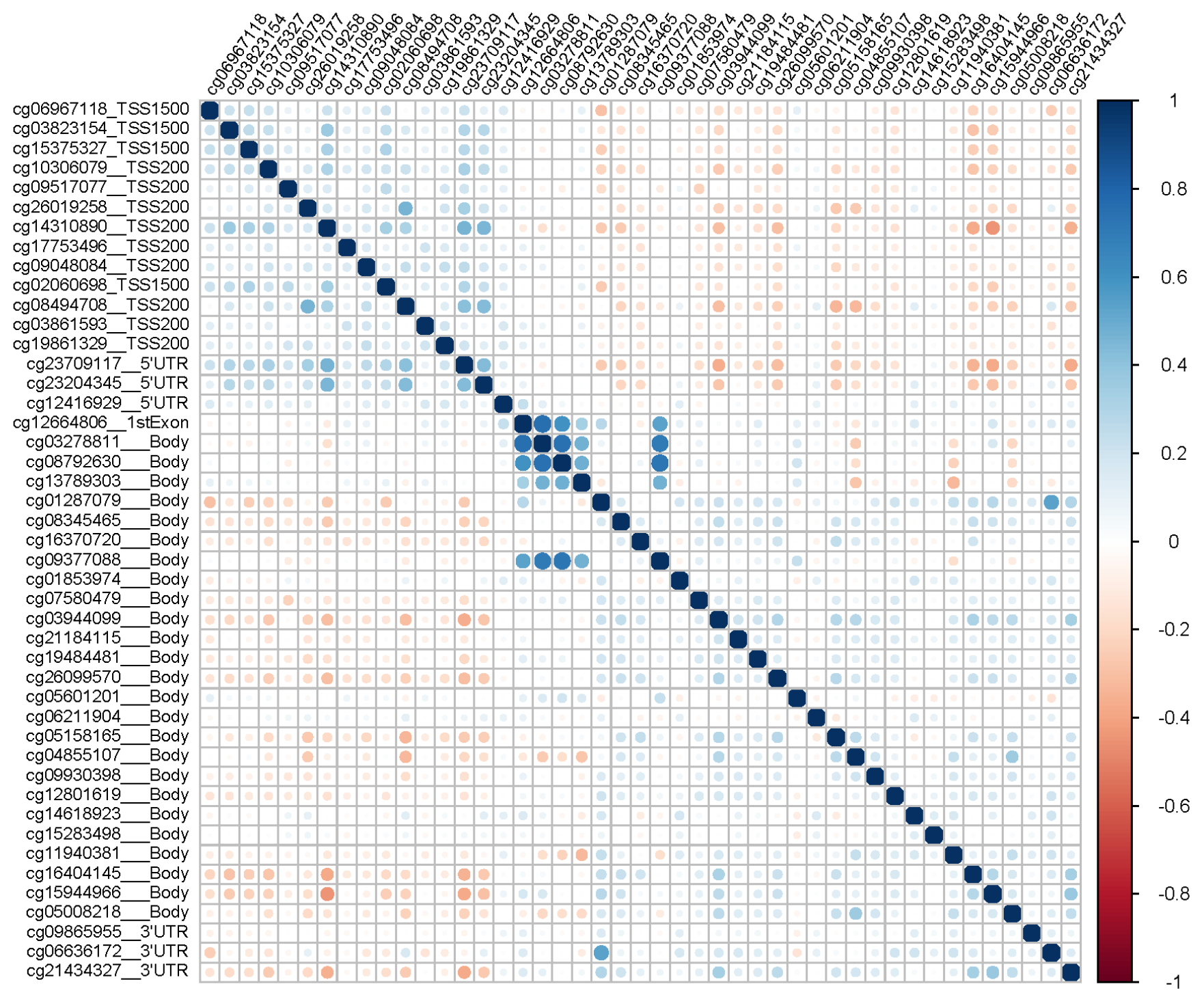

Figure 2. The Pearson correlation plots of methylation values of 3481 control participants at the 45 CpGs across FOXO3.

\subsection{Associations with Cancer Risk}

We found no evidence to support that methylation at any of the 45 sites in FOXO3 was associated with risk of cancer overall or specific type $\left(p>1.23 \times 10^{-4}\right)$, and this finding remained the same after adjustment for lifestyle-related variables (smoking, alcohol consumption, and BMI), as in Table S4.

\subsection{Associations with Cancer Survival}

Of the $45 \mathrm{CpGs}$, we found no evidence to support an association between FOXO3 methylation and overall cancer survival (all cancer types), and all $p>1.23 \times 10^{-4}$, as in Table S5. Significant associations observed for survival from specific cancer types $\left(p<1.23 \times 10^{-4}\right)$ are shown in Table 2. These associations remained similar in models that additionally adjusted for lifestyle-related variables. Methylation at a CpG in the first exon region of FOXO3 (cg12664806, 6:108882981) was associated with survival from gastric cancer (per M-value standard deviation HR $=2.39,95 \%$ CI: $1.60-3.56, p=1.9 \times 10^{-5}$ ). Methylation at three $\mathrm{CpGs}$ was found to be associated with lung cancer survival. For these CpGs, higher methylation in the promoter region (TSS1500) was associated $\left(p<6.1 \times 10^{-5}\right)$ with shorter survival (cg03823154, HR $=1.33,95 \%$ CI: 1.16-1.52) and associated with longer survival in non-promoter region (gene body) (cg05158165, HR = 0.73, 95\% CI: 0.64-0.85; 
cg16404145, HR $=0.76,95 \%$ CI: 0.67-0.87). No associations with survival were observed for other cancer types $\left(p>1.23 \times 10^{-4}\right.$, Table S5).

Table 2. Associations between FOXO3 methylation and cancer survival.

\begin{tabular}{lccccccc}
\hline \multirow{2}{*}{ CpG CHR } & \multirow{2}{*}{ MAPINFO } & \multirow{2}{*}{ Gene Group } & \multicolumn{2}{c}{ Model 2.1 } & \multicolumn{2}{c}{ Model 2.2 } \\
\cline { 4 - 7 } & & & HR (95\%CI) & $p$ Value & HR (95\%CI) & $p$ Value & Cancer Type \\
\hline cg12664806 6 & 108882981 & 1st Exon & $2.39(1.60-3.56)$ & $1.85 \times 10^{-5}$ & $2.50(1.67-3.74)$ & $7.51 \times 10^{-6}$ & Gastric \\
\hline cg05158165 6 & 108965753 & Body & $0.73(0.64-0.85)$ & $1.92 \times 10^{-5}$ & $0.73(0.63-0.84)$ & $1.81 \times 10^{-5}$ \\
$\operatorname{cg} 038231546$ & 108879922 & TSS1500 & $1.33(1.16-1.52)$ & $5.92 \times 10^{-5}$ & $1.32(1.14-1.51)$ & $1.23 \times 10^{-4}$ & Lung \\
cg16404145 6 & 108984834 & Body & $0.76(0.67-0.87)$ & $6.08 \times 10^{-5}$ & $0.77(0.68-0.88)$ & $1.12 \times 10^{-4}$ \\
\hline
\end{tabular}

Abbreviations: CpG: cytosine-guanine dinucleotide; CHR: chromosome; MAPINFO: CpG position (genome build 37); HR: hazard ratio, which is expressed per standard deviation of methylation M-values; CI: confidence interval. Model 2.1. Mixed effect Cox model with adjustment for age, sex, country of birth, sample type and white blood cell proportions as fixed effect variables, and assay plate and slide as random effect variables. Model 2.2. Model 2.1 + additional adjustment for smoking status and pack-years, body mass index, and alcohol consumption as fixed effect variables.

\subsection{Associations with Overall Mortality}

A total of 1088 participants (Table 1) were included in the overall mortality analyses, among which 354 died during follow-up. We found no evidence of an association between FOXO3 methylation and overall or cause-specific mortality $\left(p>2.78 \times 10^{-4}\right)$, and this finding remained the same after adjustment for lifestyle-related variables (Table S6).

\section{Discussion}

To our knowledge, our study is the first to have comprehensively assessed the association of DNA methylation at FOXO3 measured in blood with major health outcomes: cancer risk (3624 cases), cancer survival (2286 deaths), and mortality in an older participant sample of the MCCS (354 deaths). Our results showed strong associations between survival from cancer and DNA methylation at several CpGs. Higher methylation in the first exon region of FOXO3 (cg12664806) was associated with shorter survival from gastric cancer. We also found that higher methylation in the promoter proximal region was associated with shorter survival from lung cancer, and in the non-promoter region with longer survival. However, no evidence of association was found at other FOXO3 $\mathrm{CpG}$ sites or for other cancer types. This might imply that the regulatory role of DNA methylation is not uniform across tissues and across methylation sites, even in a very specific genomic region. Although the known functions of $\mathrm{FOXO} 3$ are consistent with a potential role in cancer survival, further studies are required to elucidate the underlying mechanisms that would explain different roles of FOXO3 methylation across cancer types and CpG sites. As we did not find any influence of FOXO3 SNPs implicated in longevity on DNA methylation in this region, it is likely that the observed associations with survival were independent of the effects of these SNPs, and potentially act through other biological pathways. Our findings nevertheless require replication in additional studies.

Although, to our knowledge, FOXO3 blood DNA methylation has been seldom studied, other studies of longevity-associated genes have highlighted a plausible role for DNA methylation in modulating longevity. A study by Salas-Pérez et al. [45] assessed a number of candidate genes involved in longevity-regulating pathways and found that FOXO3 hypermethylation in leukocytes was associated, albeit weakly, with higher triglyceride levels and insulin resistance, which are risk factors for cancer and premature death; CpGs within six genes (MTOR, ULK1, ADCY6, IGF1R, CREB5, and RELA) were identified as being associated with metabolic variables. The study by Tang et al. [46] focused on the longevity gene SIRT6 [47] in a Chinese population sample and compared the methylation profiles of 129 long-lived individuals or their immediate relatives with those of 86 individuals without a family history of exceptional longevity; they found that lower SIRT6 promoter methylation was potentially associated with longevity. The study by Szymczak et al. [48] used whole-blood methylation profiles from 267 individuals of European ancestry (including 
71 long-lived individuals) and found that methylation at PVRL2 and ERCC1, genes located in the same genomic region (chromosome 19q) as the major longevity gene APOE [49], was associated with regulation of neurophysiological processes and cancer pathways; the authors suggested that this extended genomic region might be under both genetic and epigenetic control and be key to modulate longevity. Finally, a genome-wide methylation analysis [50] showed that differences in DNA methylation profiles between centenarians' offspring and offspring of both non-long-lived parents predominantly occurred in key genes in aging and longevity, e.g., implicated in development, regulation of transcription, or metabolism.

The major strength of our study is its prospective design and the investigation of several cancer types and outcomes. For the cancer risk analysis, the study also involved matching of cases and controls by major cancer risk variables, which helps to control for confounding and improves statistical efficiency. Matched cases and controls were placed next to each other on a same slide of the assay, at random positions, thereby minimising batch effects. The main limitation of our study is that we did not have data to demonstrate the plausibility of blood DNA methylation at $F O X O 3$ as indicative of a mechanism affecting the outcomes of our study; further functional studies are therefore required to corroborate our findings. Nevertheless, the directions of the observed associations were consistent with plausible effects, because methylation in TSS and 1st exon regions are known to cause transcriptional silencing [51]. We included in the analysis all CpGs annotated to FOXO3 by the manufacturer, but it is possible that $\mathrm{CpGs}$ located outside this window, or further away on chromosome $6 /$ across the genome, e.g., through trans-genetic effects, may have functional relevance related to FOXO3 activity. As the HM450 assay has only limited genome coverage, there may be FOXO3 CpGs of interest that we missed, but most relevant CpGs, in particular, in promoter regions and related to cancer, were selected in priority for inclusion on the assay. Although our sample size was relatively large, we could not assess risk with precision for several sample types, in particular, risk of gastric and kidney cancer $(n<200)$. The analyses of mortality in older participants were also based on a relatively small number of deaths ( $n=354$ overall, and $n=60$ for cancer-specific mortality). Because we used a relatively stringent strategy to account for multiple testing across outcomes and methylation sites, the $p$-value threshold to detect association was low. It is therefore possible that we could not detect existing associations due to lack of power. We were not able to further stratify the analysis by more specific causes of death, for example, dementia or individual cancer types. Large-scale studies that have measured DNA methylation are quite recent and future international pooling efforts could shed light on the potential role of FOXO3 methylation in causing disease. In the genetic field, studies that were able to robustly identify SNPs associated with longevity did so only through the pooling of $>30,000$ samples and a dichotomised outcome ( $>90$ th survival percentile, compared with $<60$ th survival percentage), and the magnitude of association was relatively modest, being estimated as an $8 \%$ increase for variant carriers for the SNP most strongly associated with longevity [14].

\section{Conclusions}

We conclude from our study that blood DNA methylation at FOXO3 might be associated with gastric and lung cancer survival. No evidence of associations was found for other health outcomes. Additional studies based on a larger sample size are required to replicate our findings and to clarify and extend the investigation of the role of DNA methylation as a potential mechanism linking FOXO3 to longevity.

Supplementary Materials: The following are available online at https:/ / www.mdpi.com/article/ 10.3390/cells10123384/s1. Table S1: Characteristics of the participants from eight specific studies in the MCCS sample. Table S2: Pearson correlation matrix of methylation values at the 45 FOXO3 CpGs. Table S3: Associations between methylation values at the $45 \mathrm{CpGs}$ and genetic values at the four longevity-related SNPs in FOXO3. Table S4: Associations between methylation values at the $45 \mathrm{CpGs}$ in FOXO3 and risk of cancer overall or specific type. Table S5: Associations between 
methylation values at the $45 \mathrm{CpGs}$ in $\mathrm{FOXO} 3$ and survival from cancer overall or specific type. Table S6: Associations between FOXO3 methylation and overall or cause-specific mortality.

Author Contributions: C.Y. and P.-A.D. conceived the study and conducted the data analysis. J.E.J. and E.M.W. curated the data. J.E.J. and E.M.W. conducted laboratory work. M.C.S. and G.G.G. contributed resources. P.-A.D. supervised the study. A.M.H., J.E.J., E.M.W., E.M., D.S., D.D.B., J.L.H., G.G.G., M.C.S. and P.-A.D. obtained funding. C.Y. and P.-A.D. drafted the manuscript. All authors contributed to the interpretation of the results, reviewed the final draft, and have read and agreed to the published version of the manuscript.

Funding: MCCS cohort recruitment was funded by VicHealth and Cancer Council Victoria, Australia. The MCCS was further supported by Australian NHMRC grants 209057, 251553 and 504711 and by infrastructure provided by Cancer Council Victoria. The nested case-control methylation studies were supported by the NHMRC grants 1011618, 1026892, 1027505, 1050198, 1043616 and 1074383. This work was further supported by NHMRC grants 1088405 and 1164455 . M.C.S. is a recipient of a Senior Research Fellowship from the NHMRC (GTN1155163).

Institutional Review Board Statement: The study was conducted according to the guidelines of the Declaration of Helsinki and approved by the Human Research Ethics Committee of Cancer Council Victoria (protocol code IEC \#9001, 31 December 1990).

Informed Consent Statement: All participants provided informed consent in accordance with the Declaration of Helsinki.

Data Availability Statement: Data will be made available upon reasonable request to the corresponding author.

Conflicts of Interest: The authors declare no conflict of interest.

\section{References}

1. Kenyon, C.; Chang, J.; Gensch, E.; Rudner, A.; Tabtiang, R. A C. elegans mutant that lives twice as long as wild type. Nature 1993, 366, 461-464. [CrossRef]

2. Murakami, S.; Johnson, T.E. A genetic pathway conferring life extension and resistance to UV stress in Caenorhabditis Elegans. Genetics 1996, 143, 1207-1218. [CrossRef]

3. Lin, K.; Dorman, J.B.; Rodan, A.; Kenyon, C. Daf-16: An HNF-3/fork head family member that can function to double the life-span of Caenorhabditis elegans. Science 1997, 278, 1319-1322. [CrossRef]

4. Ogg, S.; Paradis, S.; Gottlieb, S.; Patterson, G.I.; Lee, L.; Tissenbaum, H.A.; Ruvkun, G. The fork head transcription factor DAF-16 transduces insulin-like metabolic and longevity signals in C. elegans. Nature 1997, 389, 994-999. [CrossRef]

5. Willcox, B.J.; Donlon, T.A.; He, Q.; Chen, R.; Grove, J.S.; Yano, K.; Masaki, K.H.; Willcox, D.C.; Rodriguez, B.; Curb, J.D. FOXO3A genotype is strongly associated with human longevity. Proc. Nat. Acad. Sci. USA 2008, 105, 13987-13992. [CrossRef] [PubMed]

6. Anselmi, C.V.; Malovini, A.; Roncarati, R.; Novelli, V.; Villa, F.; Condorelli, G.; Bellazzi, R.; Puca, A.A. Association of the FOXO3A locus with extreme longevity in a southern Italian centenarian study. Rejuvenat. Res. 2009, 12, 95-104. [CrossRef] [PubMed]

7. Flachsbart, F.; Caliebe, A.; Kleindorp, R.; Blanché, H.; von Eller-Eberstein, H.; Nikolaus, S.; Schreiber, S.; Nebel, A. Association of FOXO3A variation with human longevity confirmed in German centenarians. Proc. Nat. Acad. Sci. USA 2009, 106, 2700-2705. [CrossRef] [PubMed]

8. Li, Y.; Wang, W.J.; Cao, H.; Lu, J.; Wu, C.; Hu, F.Y.; Guo, J.; Zhao, L.; Yang, F.; Zhang, Y.X.; et al. Genetic association of FOXO1A and FOXO3A with longevity trait in Han Chinese populations. Hum. Mol. Genet. 2009, 18, 4897-4904. [CrossRef] [PubMed]

9. Pawlikowska, L.; Hu, D.; Huntsman, S.; Sung, A.; Chu, C.; Chen, J.; Joyner, A.H.; Schork, N.J.; Hsueh, W.C.; Reiner, A.P.; et al. Association of common genetic variation in the insulin/IGF1 signaling pathway with human longevity. Aging Cell 2009, 8, 460-472. [CrossRef]

10. Kenyon, C.J. The genetics of ageing. Nature 2010, 464, 504-512. [CrossRef] [PubMed]

11. Sanese, P.; Forte, G.; Disciglio, V.; Grossi, V.; Simone, C. FOXO3 on the road to longevity: Lessons from SNPs and chromatin hubs. Comput. Struct. Biotechnol. J. 2019, 17, 737-745. [CrossRef] [PubMed]

12. Grossi, V.; Forte, G.; Sanese, P.; Peserico, A.; Tezil, T.; Lepore Signorile, M.; Fasano, C.; Lovaglio, R.; Bagnulo, R.; Loconte, D.C.; et al. The longevity SNP rs2802292 uncovered: HSF1 activates stress-dependent expression of FOXO3 through an intronic enhancer. Nucleic Acids Res. 2018, 46, 5587-5600. [CrossRef]

13. Flachsbart, F.; Dose, J.; Gentschew, L.; Geismann, C.; Caliebe, A.; Knecht, C.; Nygaard, M.; Badarinarayan, N.; ElSharawy, A.; May, S.; et al. Identification and characterization of two functional variants in the human longevity gene FOXO3. Nat. Commun. 2017, 8, 2063. [CrossRef]

14. Deelen, J.; Evans, D.S.; Arking, D.E.; Tesi, N.; Nygaard, M.; Liu, X.; Wojczynski, M.K.; Biggs, M.L.; van der Spek, A.; Atzmon, G.; et al. A meta-analysis of genome-wide association studies identifies multiple longevity genes. Nat. Commun. 2019, 10, 3669. [CrossRef] [PubMed] 
15. Broer, L.; Buchman, A.S.; Deelen, J.; Evans, D.S.; Faul, J.D.; Lunetta, K.L.; Sebastiani, P.; Smith, J.A.; Smith, A.V.; Tanaka, T.; et al. GWAS of longevity in CHARGE consortium confirms APOE and FOXO3 candidacy. J. Gerontol. Ser. A Biomed. Sci. Med. Sci. 2015, 70, 110-118. [CrossRef] [PubMed]

16. Yang, M.; Vousden, K.H. Serine and one-carbon metabolism in cancer. Nat. Rev. Cancer 2016, 16, 650-662. [CrossRef] [PubMed]

17. Brennan, K.; Flanagan, J.M. Epigenetic epidemiology for cancer risk: Harnessing germline epigenetic variation. Cancer EpiGenet. 2012, 863, 439-465.

18. Wong, E.M.; Southey, M.C.; Fox, S.B.; Brown, M.A.; Dowty, J.G.; Jenkins, M.A.; Giles, G.G.; Hopper, J.L.; Dobrovic, A. Constitutional methylation of the $B R C A 1$ promoter is specifically associated with $B R C A 1$ mutation-associated pathology in early-onset breast cancer. Cancer Prev. Res. 2011, 4, 23-33. [CrossRef] [PubMed]

19. Brennan, K.; Garcia-Closas, M.; Orr, N.; Fletcher, O.; Jones, M.; Ashworth, A.; Swerdlow, A.; Thorne, H.; Riboli, E.; Vineis, P.; et al. Intragenic ATM methylation in peripheral blood DNA as a biomarker of breast cancer risk. Cancer Res. 2012, 72, 2304-2313. [CrossRef] [PubMed]

20. Peng, S.L. Foxo in the immune system. Oncogene 2008, 27, 2337-2344. [CrossRef] [PubMed]

21. Liu, Y.; Ao, X.; Ding, W.; Ponnusamy, M.; Wu, W.; Hao, X.; Yu, W.; Wang, Y.; Li, P.; Wang, J. Critical role of FOXO3a in carcinogenesis. Mol. Cancer 2018, 17, 1-12. [CrossRef] [PubMed]

22. Hornsveld, M.; Dansen, T.B.; Derksen, P.W.; Burgering, B.M.T. Re-evaluating the role of FOXOs in cancer. Semin. Cancer Biol. 2018, 50, 90-100. [CrossRef] [PubMed]

23. Bullock, M.D.; Bruce, A.; Sreekumar, R.; Curtis, N.; Cheung, T.; Reading, I.; Primrose, J.N.; Ottensmeier, C.; Packham, G.K.; Thomas, G.; et al. FOXO3 expression during colorectal cancer progression: Biomarker potential reflects a tumour suppressor role. Br. J. Cancer 2013, 109, 387-394. [CrossRef] [PubMed]

24. Qian, Z.; Ren, L.; Wu, D.; Yang, X.; Zhou, Z.; Nie, Q.; Jiang, G.; Xue, S.; Weng, W.; Qiu, Y.; et al. Overexpression of FoxO3a is associated with glioblastoma progression and predicts poor patient prognosis. Int. J. Cancer 2017, 140, 2792-2804. [CrossRef] [PubMed]

25. Shen, Z.; Zhou, L.; Zhang, C.; Xu, J. Reduction of circular RNA Foxo3 promotes prostate cancer progression and chemoresistance to docetaxel. Cancer Lett. 2020, 468, 88-101. [CrossRef] [PubMed]

26. Yang, W.; Du, W.W.; Li, X.; Yee, A.J.; Yang, B.B. Foxo3 activity promoted by non-coding effects of circular RNA and Foxo3 pseudogene in the inhibition of tumor growth and angiogenesis. Oncogene 2016, 35, 3919-3931. [CrossRef]

27. Du, W.W.; Fang, L.; Yang, W.; Wu, N.; Awan, F.M.; Yang, Z.; Yang, B.B. Induction of tumor apoptosis through a circular RNA enhancing Foxo3 activity. Cell Death Differ. 2017, 24, 357-370. [CrossRef] [PubMed]

28. Yang, T.; Li, Y.; Zhao, F.; Zhou, L.; Jia, R. Circular RNA Foxo3: A Promising Cancer-Associated Biomarker. Front. Genet. 2021, 12, 405. [CrossRef] [PubMed]

29. Milne, R.L.; Fletcher, A.S.; MacInnis, R.J.; Hodge, A.M.; Hopkins, A.H.; Bassett, J.K.; Bruinsma, F.J.; Lynch, B.M.; Dugué, P.A.; Jayasekara, H.; et al. Cohort profile: The Melbourne collaborative cohort study (health 2020). Int. J. Epidemiol. 2017, 46, 1757-1757i. [CrossRef] [PubMed]

30. Dugué, P.A.; Bassett, J.K.; Joo, J.E.; Jung, C.H.; Ming Wong, E.; Moreno-Betancur, M.; Schmidt, D.; Makalic, E.; Li, S.; Severi, G.; et al. DNA methylation-based biological aging and cancer risk and survival: Pooled analysis of seven prospective studies. Int. J. Cancer 2018, 142, 1611-1619. [CrossRef] [PubMed]

31. Dugué, P.A.; Bassett, J.K.; Wong, E.M.; Joo, J.E.; Li, S.; Yu, C.; Schmidt, D.F.; Makalic, E.; Doo, N.W.; Buchanan, D.D.; et al. Biological aging measures based on blood DNA methylation and risk of cancer: A prospective study. JNCI Cancer Spectr. 2021, 5, pkaa109. [CrossRef] [PubMed]

32. Dugué, P.A.; Hodge, A.M.; Wong, E.M.; Joo, J.E.; Jung, C.H.; Hopper, J.L.; English, D.R.; Giles, G.G.; Milne, R.L.; Southey, M. Methylation marks of prenatal exposure to maternal smoking and risk of cancer in adulthood. Int. J. Epidemiol. 2021, 50, 105-115. [CrossRef] [PubMed]

33. Dugué, P.A.; English, D.R.; MacInnis, R.J.; Jung, C.H.; Bassett, J.K.; FitzGerald, L.M.; Wong, E.M.; Joo, J.E.; Hopper, J.L.; Southey, M.C.; et al. Reliability of DNA methylation measures from dried blood spots and mononuclear cells using the HumanMethylation450k BeadArray. Sci. Rep. 2016, 6, 30317. [CrossRef]

34. Du, P.; Zhang, X.; Huang, C.C.; Jafari, N.; Kibbe, W.A.; Hou, L.; Lin, S.M. Comparison of Beta-value and M-value methods for quantifying methylation levels by microarray analysis. BMC Bioinform. 2010, 11, 587. [CrossRef] [PubMed]

35. Amos, C.I.; Dennis, J.; Wang, Z.; Byun, J.; Schumacher, F.R.; Gayther, S.A.; Casey, G.; Hunter, D.J.; Sellers, T.A.; Gruber, S.B.; et al. The OncoArray Consortium: A network for understanding the genetic architecture of common cancers. Cancer Epidemiol. Prev. Biomark. 2017, 26, 126-135. [CrossRef]

36. Das, S.; Forer, L.; Schönherr, S.; Sidore, C.; Locke, A.E.; Kwong, A.; Vrieze, S.I.; Chew, E.Y.; Levy, S.; McGue, M.; et al. Nextgeneration genotype imputation service and methods. Na. Genet. 2016, 48, 1284-1287. [CrossRef] [PubMed]

37. Howie, B.N.; Donnelly, P.; Marchini, J. A flexible and accurate genotype imputation method for the next generation of genomewide association studies. PLoS Genet. 2009, 5, e1000529. [CrossRef] [PubMed]

38. Dugué, P.A.; Yu, C.; McKay, T.; Wong, E.M.; Joo, J.E.; Tsimiklis, H.; Hammet, F.; Mahmoodi, M.; Theys, D.; Hopper, J.L.; et al. VTRNA2-1: Genetic variation, heritable methylation and disease association. Int. J. Mol. Sci. 2021, 22, 2535. [CrossRef]

39. Houseman, E.A.; Accomando, W.P.; Koestler, D.C.; Christensen, B.C.; Marsit, C.J.; Nelson, H.H.; Wiencke, J.K.; Kelsey, K.T. DNA methylation arrays as surrogate measures of cell mixture distribution. BMC Bioinform. 2012, 13, 86. [CrossRef] [PubMed] 
40. Dugué, P.A.; Jung, C.H.; Joo, J.E.; Wang, X.; Wong, E.M.; Makalic, E.; Schmidt, D.F.; Baglietto, L.; Severi, G.; Southey, M.C.; et al. Smoking and blood DNA methylation: An epigenome-wide association study and assessment of reversibility. EpiGenet 2020, 15, 358-368. [CrossRef] [PubMed]

41. Dugué, P.A.; Wilson, R.; Lehne, B.; Jayasekara, H.; Wang, X.; Jung, C.H.; Joo, J.E.; Makalic, E.; Schmidt, D.F.; Baglietto, L.; et al. Alcohol consumption is associated with widespread changes in blood DNA methylation: Analysis of cross-sectional and longitudinal data. Addict. Biol. 2021, 26, e12855. [CrossRef]

42. Geurts, Y.M.; Dugué, P.A.; Joo, J.E.; Makalic, E.; Jung, C.H.; Guan, W.; Nguyen, S.; Grove, M.L.; Wong, E.M.; Hodge, A.M.; et al. Novel associations between blood DNA methylation and body mass index in middle-aged and older adults. Int. J. Obes. 2018, 42, 887-896. [CrossRef] [PubMed]

43. Therneau, T.M.; Grambsch, P.M.; Pankratz, V.S. Penalized survival models and frailty. J. Comput. Graph. Stat. 2003, 12, 156-175. [CrossRef]

44. Thiébaut, A.C.; Bénichou, J. Choice of time-scale in Cox's model analysis of epidemiologic cohort data: A simulation study. Stat. Med. 2004, 23, 3803-3820. [CrossRef] [PubMed]

45. Salas-Pérez, F.; Ramos-Lopez, O.; Mansego, M.L.; Milagro, F.I.; Santos, J.L.; Riezu-Boj, J.I.; Martínez, J.A. DNA methylation in genes of longevity-regulating pathways: Association with obesity and metabolic complications. Aging 2019, 11, 1874. [CrossRef] [PubMed]

46. Tang, X.; Wei, Y.; Wang, J.; Chen, S.; Cai, J.; Tang, J.; Xu, X.; Long, B.; Yu, G.; Zhang, Z.; et al. Association between SIRT6 methylation and human longevity in a Chinese population. Public Health Genom. 2020, 23, 190-199. [CrossRef] [PubMed]

47. Vitiello, M.; Zullo, A.; Servillo, L.; Mancini, F.P.; Borriello, A.; Giovane, A.; Della Ragione, F.; D’Onofrio, N.; Balestrieri, M.L. Multiple pathways of SIRT6 at the crossroads in the control of longevity, cancer, and cardiovascular diseases. Aging Res. Rev. 2017, 35, 301-311. [CrossRef] [PubMed]

48. Szymczak, S.; Dose, J.; Torres, G.G.; Heinsen, F.A.; Venkatesh, G.; Datlinger, P.; Nygaard, M.; Mengel-From, J.; Flachsbart, F.; Klapper, W.; et al. DNA methylation QTL analysis identifies new regulators of human longevity. Hum. Mol. Genet. 2020, 29, 1154-1167. [CrossRef]

49. Schächter, F.; Faure-Delanef, L.; Guénot, F.; Rouger, H.; Froguel, P.; Lesueur-Ginot, L.; Cohen, D. Genetic associations with human longevity at the APOE and ACE loci. Nat. Genet. 1994, 6, 29-32. [CrossRef]

50. Gentilini, D.; Mari, D.; Castaldi, D.; Remondini, D.; Ogliari, G.; Ostan, R.; Bucci, L.; Sirchia, S.M.; Tabano, S.; Cavagnini, F.; et al. Role of epigenetics in human aging and longevity: Genome-wide DNA methylation profile in centenarians and centenarians' offspring. Age 2013, 35, 1961-1973. [CrossRef] [PubMed]

51. Brenet, F.; Moh, M.; Funk, P.; Feierstein, E.; Viale, A.J.; Socci, N.D.; Scandura, J.M. DNA methylation of the first exon is tightly linked to transcriptional silencing. PLoS ONE 2011, 6, e14524. [CrossRef] [PubMed] 